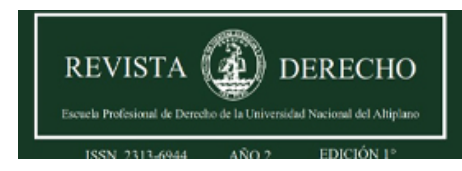

Revista de Derecho

ISSN: 2313-6944

ISSN: 2707-9651

revistaderecho@unap.edu.pe

Universidad Nacional del Altiplano

Perú

\title{
LA CRIMINALIZACIÓN Y JUDICIALIZACIÓN DE LAS PROTESTAS SOCIALES EN EL PERÚ EN TIEMPOS DE PANDEMIA (COVID-19)
}

Paredes Ponce, Dyanna Solange; Talavera Quispe, Gabriel Dennis; Quispe Humpiri, Anel America;

Anquise Jaliri, Gloria Carolina; Colquehuanca Callata, Rubí Marjorie; Ponce Moreno, Bedzabel Sollange; Carcausto Quispe, Wilfredo Alain

LA CRIMINALIZACIÓN Y JUDICIALIZACIÓN DE LAS PROTESTAS SOCIALES EN EL PERÚ EN TIEMPOS DE PANDEMIA (COVID-19)

Revista de Derecho, vol. 6, núm. 2, 2021

Universidad Nacional del Altiplano, Perú

Disponible en: https://www.redalyc.org/articulo.oa?id=671870938010

DOI: https://doi.org/10.47712/rd.2021.v6i2.146

\section{(c) (1)}

Esta obra está bajo una Licencia Creative Commons Atribución 4.0 Internacional. 
Dyanna Solange Paredes Ponce, et al. La CRIMinaliZación y JUdicialización de LaS PROTESTaS SOCIALE...

Artículos de investigaciones realizadas por estudiantes con docentes

\section{LA CRIMINALIZACIÓN Y JUDICIALIZACIÓN DE LAS PROTESTAS SOCIALES EN EL PERÚ EN TIEMPOS DE PANDEMIA (COVID-19)}

\section{THE CRIMINALIZATION AND JUDICIALIZATION OF SOCIAL PROTESTS IN PERU IN TIMES OF PANDEMIC (COVID-19)}

Dyanna Solange Paredes Ponce

Universidad Nacional del Altiplano, Perú

lawsolange20@gmail.com

iD https://orcid.org/0000-0003-4713-2687

Gabriel Dennis Talavera Quispe

Universidad Nacional del Altiplano, Perú

detaqui17@gmail.com

iD https://orcid.org/0000-0001-7220-1950

Anel America Quispe Humpiri

Universidad Nacional del Altiplano, Perú

anelamericaqh@gmail.com

iD https://orcid.org/0000-0002-5316-7854

Gloria Carolina Anquise Jaliri

Universidad Nacional del Altiplano, Perú

caroanquise22@gmail.com

(iD) https://orcid.org/0000-0003-2626-7902

Rubi Marjorie Colquebuanca Callata

Universidad Nacional del Altiplano, Perú

rubimarjoriecolquehuancacallat@gmail.com

iD https://orcid.org/0000-0002-4445-7526

Bedzabel Sollange Ponce Moreno

Universidad Nacional del Altiplano, Perú

sollangebed@gmail.com

Wilfredo Alain Carcausto Quispe

Universidad Nacional del Altiplano, Perú

alaincarcausto777@gmail.com
DOI: https://doi.org/10.47712/rd.2021.v6i2.146

Redalyc: https://www.redalyc.org/articulo.oa? id $=671870938010$
Recepción: 05 Marzo 2021

Aprobación: 01 Agosto 2021 Publicación: 04 Agosto 2021

\section{Resumen:}

Notas DE AUTOR

lawsolange20@gmail.com 
Con el desarrollo de la presente investigación, se tiene por objetivo, caracterizar críticamente el complejo entramado legal que articula la política de criminalización de las protestas sociales en el Perú.

El artículo hace una descripción del marco normativo en relación al uso de la fuerza estatal en conflictos sociales y pone énfasis en la naturaleza violenta del derecho como enfoque teórico e intenta mostrar de qué manera el sistema jurídico, antes que garante es productor de violaciones a los derechos humanos.

La metodología empleada es, por un lado, dogmática cuando analiza normas y otros documentos legales y, por otro, interdisciplinaria cuando compara leyes con evidencia recogida en entrevistas, documentos, encuestas y bases de datos.

Palabras ClaVe: Criminalización, judicialización, protesta, social, fuerza, estado, emergencia, sanitaria.

\section{Abstract:}

With the development of this research, the objective is to characterize the complex legal framework that articulates the policy of criminalization of social protests in Peru. The article describes the normative framework in relation to the use of state force in social conflicts and emphasizes the violent nature of the law as a theoretical approach and tries to show how the legal system, before being a guarantor, is a producer of human rights violations. The methodology used is, on the one hand, dogmatic when analyzing norms and other legal documents and, on the other, interdisciplinary when comparing laws with evidence collected in interviews, documents, surveys and databases.

KEYWORDS: Criminalization, judicialization, social, protests, state, force, health, emergency.

\section{INTRODUCCIÓN}

En general, cuando se debate sobre las respuestas de la sociedad civil a la pandemia se piensa dicotómicamente, es decir, se acató civilizadamente la cuarentena decretada por el gobierno o reinó la irresponsabilidad. En el mejor de los casos se entiende que en países donde la informalidad laboral es alta es lógico que mucha gente desacate la norma para sobrevivir. Sin embargo, se han visibilizado otras dos respuestas que también son frecuentes, que son la protesta y la organización de soluciones.

La pandemia ha cambiado drásticamente las condiciones para todo tipo de acción colectiva. Sin embargo, el peso de la desigualdad que se multiplica en este contexto ha forzado a que, a pesar del riesgo, mucha gente vuelva a manifestarse en las calles. La gran masa de protestas callejeras actuales en el mundo es por bioseguridad y subsistencia.

Pero la sociedad peruana se caracteriza hoy por ser el lugar de la protesta permanente, reflejo de la ausencia de canales institucionales eficaces para resolver conflictos. Si bien la pandemia ha significado un freno al incremento de conflictos sociales, sí se han seguido dando protestas callejeras en respuesta a los nuevos retos que ha generado.

En Perú, si bien no hay grandes sindicatos ni movimientos sociales que presionen por políticas sociales, sí hay pequeñas asociaciones y colectivos que pelean día a día por no perder lo poco que tienen. No confiamos en las instituciones y empujamos la política desde las calles. Frente a la pandemia, ese escenario no ha cambiado mucho. En este artículo veremos a la protesta como respuesta para empujar al gobierno a atender problemas urgentes, así como soluciones por parte de sectores más organizados y redes de solidaridad.

En el marco de una investigación más extensa sobre criminalización de la protesta, presentamos un análisis del marco regulatorio sobre el uso de la fuerza y otras normas que impactan en los conflictos sociales en el Perú en tiempos de pandemia. El objetivo es identificar las normas en todos los aspectos que atañen al ejercicio del derecho a la protesta y reflexionar acerca de sus alcances, limitaciones y contradicciones.

La Marcha Nacional de la semana del 9 al 15 de noviembre del año 2020, contra la vacancia presidencial, el Congreso y la asunción de Manuel Merino como presidente, fue algo atípica para el historial de protestas en Perú. Desde las primeras semanas se destacó la presencia de miles de jóvenes, sobre todo en la ciudad de Lima, que desde las convocatorias por redes sociales se habían concentrado en el Centro Histórico, pero también estaban presentes y organizados en distintas instituciones como por ejemplo la Pontificia 
Universidad Católica del Perú, institución de la cual egresó la socióloga Noelia Chávez quién lo bautizó como la "Generación del Bicentenario".

El análisis se centrará principalmente en lo ocurrido en tiempo de pandemia debido al Covid-19 durante el 2020, para empezar, realizamos aproximaciones a los conceptos de criminalización y de protesta social. Luego, presentamos las principales normas nacionales e internacionales que regulan el uso de la fuerza de los agentes del Estado peruano, así como la regulación y el establecimiento del estado de emergencia, mostramos la situación actual de la legislación penal con respecto a la represión de las protestas sociales, especialmente a los delitos referidos contra el orden público principalmente.

La metodología empleada es dogmática, a través del análisis de normas jurídicas y otros documentos legales. Por otra parte, la metodología es también crítica, especialmente desde la perspectiva de la sociología del derecho. El objetivo principal es realizar una descripción densa de la legalidad vigente y sus modificaciones más importantes que permita mostrar la naturaleza violenta del derecho frente a la disidencia social o, en otras palabras, la tendencia hacia el endurecimiento y mayor selectividad del sistema punitivo del Estado, asimismo se utilizará el método mixto, el cual a su vez combina dos criterios, uno de ellos es cualitativo y el otro es cuantitativo; recurriendo a fuentes diversas como entrevistas, observación participante, bases de datos públicos y, en algunos casos, se presenta datos novedosos, elaborados especialmente para este artículo con lo cual se busca darle mayor profundidad a la presente investigación, con ello realizar un análisis integral y a la vez se tendrá en cuenta un enfoque desde la criminología crítica.

\section{LA CRIMINALIZACIÓN DE LA PROTESTA SOCIAL EN EL PERÚ}

Según el autor (Quiroz, 2019) podríamos definir a la protesta como una acción hecha por un conjunto de personas que va orientada a persuadir o influenciar las decisiones de individuos de una sociedad con el objetivo de lograr sus propósitos.

En aquella definición llegamos a encontrar dos componentes importantes, uno de ellos es que la protesta es una acción ejercida por una colectividad, lo cual quiere decir que, va a ser realizada por un grupo plural de personas, de lo que podemos entender que este tipo de accionar de ninguna manera podría llegar a consolidarse de forma particular, sino que debe concentrar un número significativo de individuos en un determinado lugar. Además de que, puede darse el caso, de que, este acto conjunto puede darse de manera prefijada, establecida con anterioridad o puede surgir en el momento, ósea puede configurarse de forma espontánea. También es necesario agregar que, las personas que participan activamente en este acto conjunto, no necesariamente poseen un rasgo o procedencia similar, ósea, pueden provenir de distintos grupos sociales, distinto género, religión, posición socioeconómica, etnia, ideología, etc. Sin embargo, les corresponde intervenir o ser parte, bajo una misma finalidad, que ellos persiguen y comparten.

El segundo componente, hace referencia a que los sujetos que intervienen en la acción conjunta están en la búsqueda de materializar sus objetivos, esto lo lograrán a través de terceros, es por ello que los intervinientes buscan persuadir e influenciar en la toma de decisiones de los terceros. En otras palabras, los que participan en las protestas no pueden lograr sus objetivos por sí solos, pero los que sí pueden hacer reales sus objetivos son los terceros. También debemos recalcar que la acción de protesta es un incentivo que lleve a los protestantes a obtener una respuesta rápida o inmediata, más por el contrario lo que llevó a que se tomen acciones conjuntas es claramente la ausencia de una respuesta positiva. En pocas palabras se busca persuadir al tercero, con la finalidad de que este adopte o materialice la decisión que persigue la multitud.

En el contexto peruano, la libertad de expresión y los derechos y libertades conexos se han visto particularmente amenazados por la criminalización de la protesta social. Es decir, la creciente tensión entre el ejercicio democrático de los derechos de libertad de expresión canalizados a través de las libertades de reunión, asociación y protesta para reivindicar legítimas demandas que sectores de la población civil sienten 
vulneradas vis a vis la represión penal de conductas que supuestamente encajaría como delitos atentatorios contra el orden público y aquellas que encajarían como criminalización de la protesta social. (Bertoni,2013)

En efecto, el presente gobierno de Francisco Sagasti Hochhausler, a partir de once decretos a través de los cuales el Congreso le ha otorgado facultades legislativas, busca reprimir de forma más severa el derecho de la libertad de expresión y derechos y libertades conexos los cuales se encuentran no sólo regulados a nivel de instrumentos internacionales (tanto de Naciones Unidas como de la Organización de Estados Americanos) vinculantes para el Perú, sino en la propia Constitución Política como derechos fundamentales. Esta represión obedece al creciente descontento de importantes sectores de la ciudadanía los cuales frente a la adopción de políticas que ellos estiman como limitativas de sus derechos, hacen uso de la protesta social y de la diseminación de críticas al gobierno de turno como canales para defender sus derechos vulnerados.

La manera en la cual se destina la legislación penal competente es alarmante cada vez que se produce una suerte de persecución judicial de distintos actores de la sociedad civil que comprenden un espectro amplio, desde defensores de derechos humanos incluso miembros de comunidades nativas y campesinas. Tal persecución se materializa a través de ciertas imputaciones fiscales y decisiones judiciales cuando, arbitrariamente, aplican categorías penales tales como autoría mediata, una lectura demasiado amplia de los tipos penales en cuestión e inadecuada valoración de material probatorio. Todo ello origina que un creciente número de personas se encuentren bajo órdenes de arresto o arrestados y en proceso.

La aplicación más severa de la legislación penal en la materia también generó un saldo trágico. En efecto, debido a mayores licencias otorgadas a las fuerzas del orden para controlar protestas y manifestaciones, la desproporción y exceso originaron un importante número de civiles heridos y fallecidos. Todo ello promueve un clima en el cual se busca infundir temor entre actores de la sociedad civil que pretenden, a través del ejercicio democrático de su libertad de expresión y otros derechos conexos, defender una amplia gama de derechos relacionados principal pero no exclusivamente a sus derechos sociales, económicos y culturales. (Bertoni, 2013).

La Comisión Interamericana de Derechos Humanos, que hace suya la jurisprudencia constante de la Corte Europea de Derechos Humanos, dice: "La libertad de expresión constituye uno de los pilares esenciales de una sociedad democrática y una condición fundamental para su progreso y para el desarrollo personal de cada individuo. Dicho derecho no sólo debe garantizarse en lo que respecta a la difusión de información o ideas que son recibidas favorablemente o que son consideradas como inofensivas o indiferentes, sino también en lo que toca a las que ofenden, resultan ingratas o perturban al Estado o a cualquier otro sector de la población. Tales son las demandas del pluralismo, la tolerancia y el espíritu de apertura, sin las cuales no existe una sociedad democrática”. (Relatoría Especial para la Libertad de Expresión, 2019).

Según los Estándares sobre los derechos involucrados en la protesta social y las obligaciones que deben guiar la respuesta estatal elaborados por la Relatoría Especial para la Libertad de Expresión de la Comisión Interamericana de Derechos Humanos, los derechos involucrados en el contexto de las protestas sociales, son:

1. El derecho a la libertad de expresión. Este derecho está consagrado en el artículo IV de la Declaración Americana de los Derechos y Deberes del Hombre; en el artículo 13 de la Convención Americana sobre Derechos Humanos. Esta Comisión ha considerado en numerosas ocasiones que "las manifestaciones públicas como ejercicio de la libertad de expresión”. Esto porque la expresión de opiniones, difusión de información y articulación de demandas constituyen objetivos centrales de las protestas. Al respecto, la CIDH y su Relatoría Especial para la Libertad de Expresión han reiterado que "la libertad de expresión se inserta en el orden público primario y radical de la democracia, que no es concebible sin el debate libre y sin que la disidencia tenga pleno derecho de manifestarse". En este sentido, el derecho a manifestarse está protegido tanto por el derecho a la libertad de expresión.

2. El Derecho de reunión. La protesta social también encuentra protección en el derecho de reunión consagrado en el Artículo XXI de la Declaración Americana de los Derechos y Deberes del Hombre; Artículo 15 de la Convención Americana sobre Derechos Humanos. El derecho de reunión protege la congregación 
pacífica, intencional y temporal de personas en un determinado espacio para el logro de un objetivo común, incluida la protesta. Como tal, es indispensable para la expresión colectiva de las opiniones y puntos de vista de las personas. El ejercicio del derecho de reunión tiene una importancia esencial para la consolidación de la vida democrática de las sociedades y, por tanto, reviste un interés social imperativo.

3. El Derecho a la libertad de asociación. La protesta suele ser un importante medio de acción y de prosecución de objetivos legítimos por parte organizaciones y colectivos, y como tal también puede encontrarse protegida por el derecho a la libertad de asociación previsto en el artículo XXII de la Declaración Americana de los Derechos y Deberes del Hombre; artículo 16 de la Convención Americana sobre Derechos Humanos. Protección que, por otra parte, tiene dimensiones específicas, como los derechos sindicales y el derecho a la huelga. El Consejo de Derechos Humanos ya ha reconocido el vínculo entre la libertad de asociación y la protesta al expresar que "otros derechos que pueden ser aplicables en caso de protestas pacíficas incluyen, por ejemplo, el derecho a la libertad de asociación”. La Corte Interamericana de Derechos Humanos (en adelante, "Corte Interamericana") ha señalado que la libertad de asociación "presupone el derecho de reunión y se caracteriza por habilitar a las personas para crear o participar en entidades $\mathrm{u}$ organizaciones con el objeto de actuar colectivamente para la consecución de los más diversos fines, siempre y cuando éstos sean legítimos". Esto implica el "derecho a agruparse con la finalidad de buscar la realización común de un fin lícito, sin presiones o intromisiones que puedan alterar o desnaturalizar dicha finalidad”.

4. La Libertad sindical y derecho a la huelga: El derecho a la libertad de asociación tiene dimensiones específicas cuando se trata de determinados grupos y colectivos o formas específicas de protesta. Un ejemplo de ello son los sindicatos y la huelga, respectivamente. En este campo el derecho a la asociación está especialmente protegido por el artículo 8 del Protocolo Adicional a la Convención Americana en Materia de Derechos Económicos, Sociales y Culturales - "Protocolo de San Salvador". El derecho de libertad de asociación sindical consiste en "la facultad de constituir organizaciones sindicales y poner en marcha su estructura interna, actividades y programa de acción, sin intervención de las autoridades públicas que limite o entorpezca el ejercicio del respectivo derecho". El derecho a la huelga es una de las expresiones de este derecho, y ha sido considerada una de las formas más comunes de ejercicio del derecho a la protesta. En el mismo sentido debe interpretarse la protección específica de la que gozan las formas de asociación y organización de los pueblos indígenas conforme las Declaración de las Naciones Unidas sobre los derechos de los pueblos indígenas, y sus formas de manifestación y protesta cuando ellas están relacionadas con derechos especialmente protegidos como por ejemplo su identidad cultural y sus tierras a formar parte en asuntos públicos (artículo 25)". La protesta como forma de participación en los asuntos públicos es especialmente relevante para los grupos de personas históricamente discriminadas o en condiciones de marginalización.

6. Los Derechos económicos, sociales y culturales: Asimismo, la protesta es un mecanismo esencial para garantizar los derechos económicos, sociales, culturales y ambientales. La lucha por el derecho a la tierra, el derecho al medio ambiente sano, las manifestaciones contra reformas económicas y contra la flexibilización laboral, entre muchas otras, han llevado a miles de defensoras y defensores, líderes estudiantiles, sociales y rurales a organizarse con el fin de luchar por la efectividad de sus derechos. Los sectores más empobrecidos de nuestro hemisferio confrontan políticas y acciones discriminatorias, su acceso a información sobre la planificación y ejecución de medidas que afectan sus vidas diarias es incipiente y en general los canales tradicionales de participación para hacer públicas sus denuncias se ven muchas veces cercenados. Ante este escenario, en muchos países del hemisferio, la protesta y movilización social se han constituido como herramientas de petición a la autoridad pública y también como canales de denuncias públicas sobre abusos o violaciones a los derechos humanos.

$\mathrm{Al}$ hacer un análisis de los derechos relacionados con las protestas y manifestaciones, es importante mencionar que las violentas o negativas respuestas por parte del Estado hacia la población manifestante no solo llega a conculcar los derechos anteriormente señalados, sino que puede llegar a afectar los derechos fundamentales como lo es el derecho a la vida, hay una afectación cuando hay una represión violenta por 
parte de las fuerzas del orden como se vivió en el Perú, a consecuencia de ello se tuvo la muerte de dos jóvenes universitarios Brayan Pintado e Inti Sotelo, por otro lado también se afecta la integridad física como sucedió con muchos otros jóvenes que participaron de las protestas, los cuales resultaron con heridas graves en su cuerpo físico a consecuencia del uso de perdigones por parte de la policía, añadido a ello también está el derecho a la seguridad personal o el derecho a la libertad, tras las declaraciones públicas de muchos jóvenes universitarios, coincidieron en que muchos de ellos no llegaron a sus hogares luego de concurrir a las manifestaciones, la población se unió y se hicieron difusiones con sus fotografías para localizarlos, días después fueron apareciendo y todos ellos mencionaron que la policía de los había llevado, entonces con estas situaciones notamos que también se afectan derechos fundamentales en el desarrollo de las protestas sociales.

\section{La protesta social}

Decimos que la protesta es un acto, una actividad, una conducta del individuo que está en contra de una decisión tomada por el Estado o, de manera más amplia, por el statu quo. (Manzo, 2018)

Según (Quintero, 2019), nos dice sobre la protesta que, esta tiende a ponerse más interesante cuando los jueces y juristas abandonan la idea de que hay que limitar los derechos en nombre del bien común o de la eficiencia económica y pasan a sostener que, lo que ellos proponen es limitar los derechos de los manifestantes, pero sólo en nombre de los derechos de los demás individuos. Enfrentándose un derecho con otro derecho, es cierto entonces, que proponemos limitar ciertos derechos, pero lo que ocurre en este caso es que el derecho de los manifestantes choca, con los derechos de los demás. La pregunta es "dónde terminan mis derechos" es una pregunta que no obtiene respuesta en la perogrullada "donde comienzan los de los demás". (Manzo, 2018)

\section{El derecho a la protesta}

En el caso peruano, el derecho a la protesta presenta estos elementos:

- Carácter subjetivo. Aun cuando cada ciudadano lo posee en abstracto, es ejercido por un grupo.

- Carácter temporal. El tribunal peruano no toca aspectos de protestas que puedan prolongarse en el tiempo, pero sí hace alusión a una eventual periodicidad en la cual pudiera presentarse la situación fáctica.

- Finalidad lícita. Semejante a como está expuesto en el resto de los países analizados.

- Necesidad de un aspecto espacial específico en donde se desenvuelve la protesta, lo que deja por fuera ciertas protestas con particularidades diferentes.

- Eficacia inmediata. Está vinculada a la notificación de la protesta, lo que no la convierte en un requisito sine qua non para llevarla a cabo. (Manzo, 2018)

\section{Los tres derechos fundamentales de la protesta}

Por otro lado, se considera que el derecho a la protesta contiene o incluye tres derechos:

Primero, se encuentra el derecho a la reunión pacífica que está concebido en varios artículos de convenciones o tratados internacionales tales como:

- La Declaración Universal de Derechos Humanos de 1948 (Artículo 20)

- La Declaración Americana de los Derechos y Deberes del Hombre de 1948 (Artículo 21).

- El Pacto Internacional de Derechos Civiles y Políticos de 1966 (Artículo 21).

- La Convención Americana de Derechos Humanos (Artículo 15).

- La Convención Internacional sobre la Eliminación de todas las formas de Discriminación Racial de 1965

(Artículo 5).

- La Convención sobre los Derechos del Niño (Artículo 15). 
Segundo, un derecho contemplado en la protesta social es la libertad de expresión, empero, está atravesando por la dualidad entre aquel que participa en una protesta y aquel que no lo hace. En tal sentido, podría hablarse de la vulneración de un derecho, mientras se protege otro. Tanto a nivel individual como colectivo la libertad, es un derecho fundamental cuyo objetivo es lograr que todas las personas tengan derecho a buscar, recibir o difundir sus opiniones, de cualquier índole de forma libre y sin ningún tipo de discriminación.

Tercero, se encuentra el derecho a la huelga, que concierne directamente a los trabajadores. En esa medida, lo que contempla la Organización Internacional del Trabajo (OIT) es que, los empleados tienen todo el derecho a manifestar de manera pacífica sus inconformidades frente a las condiciones laborales que viven a diario.

En definitiva, es necesario garantizar que la protesta social sea una herramienta para los ciudadanos y ciudadanas en los escenarios políticos, sociales y económicos que ponen en riesgo sus necesidades e intereses colectivos. Cuando un gobernante incumple, cuando olvida los pactos internacionales, cuando viola los derechos humanos, entre otra serie de inconformidades, es normal que la ciudadanía reaccione.

Yallí es clave que las manifestaciones pacíficas, como están contempladas en los protocolos internacionales, se den en el marco del respeto de ambas partes. Claro está que, en la práctica tanto el Estado como los sectores más radicales, terminan haciendo uso de la violencia ya sea por incitación de uno u otro bando. (Quintero, 2019)

\section{TENDENCIA SOCIO CRIMINOLÓGICA}

La compleja y variada interacción social del ser humano es un tema que estudia la sociología. En esa línea de pensamiento, el individuo que se forma, vive y convive dentro de una determinada sociedad, se verá moldeado según a las características que pueda percibir de tal realidad y es en este entender es que se han desarrollado concepciones diversas para explicar la conducta delictiva y una visión social rumbo a la mejor comprensión criminológica.

En el Perú se han visto reflejados dichas expresiones debido a que la sociedad ha concebido a la protesta social como única vía de solución frente a determinadas situaciones que resultan injustas y que causan indignación desembocando así en protestas sociales por ejemplo la Marcha de la Generación del Bicentenario.

Así la sociología se constituye como el estudio de la vida social humana, de los grupos y sociedades, en una perspectiva sistemática, rigurosa y científica. (Solís, 2017).

\section{Factores macrosociales del delito y la conducta antisocial}

Para el estudio criminológico y en correlación sociológico del delito debemos partir de encuadrar el comportamiento en un tipo de sociedad que será materia de estudio, sus particularidades y lo que caracteriza su superestructura que ésta a su vez se encuentra condicionada también a los diversos fenómenos microsociales (relaciones sociales).

$\mathrm{Al}$ respecto la sociedad peruana como se demostrará ampliamente líneas abajo en los resultados de la presente investigación, es una sociedad que no fomenta la práctica de valores, y es poco tolerante al diálogo, los cuales resultan imprescindibles no solo a nivel particular sino también colectivo.

En el mismo orden de ideas las relaciones de base y superestructura no son mecánicas, por el contrario, deben entenderse como dialécticas y esto en el sentido de que por ejemplo la superestructura jurídica puede también tener algún grado de influencia sobre los cambios en la base o estructura.

Finalmente, estos factores macrosociales son los vinculados a la sociedad vigente, esto quiere decir que son las que tienen importancia prioritaria, porque condicionan las características de los denominados factores "microsociales". 


\section{Factores microsociales del delito y la desviación no delictiva}

Condicionados en mayor o menor medida a las características de la estructura económico social que consideramos de factor estructural o macrosocial, son los aspectos sociales considerados como criminógenos, por ejemplo:

Los medios de comunicación y la delincuencia Importar lista

Es necesario reconocer la importancia del impacto e influencia que estos llamados "medios de comunicación masiva" tienen actualmente en nuestra sociedad peruana, sobre todo en la temática o contenido de violencia y agresividad que generarían un rol negativo en la socialización de la población.

A tener en cuenta entonces que el tipo de contenido que se transmite por los medios de comunicación social dentro de nuestra sociedad peruana se caracteriza principalmente por ofrecer imágenes de violencia, agresión, incitación al consumismo, entre otros, resaltando además que no son los mensajes que ayudarían o contribuirían al progreso social ni a la formación de personas solidarias y racionales.

Así, de este modo se vuelven estímulos indirectos que contribuyen más bien a la manifestación de conductas desviadas.

Actualmente, los medios de comunicación peruanos más preponderados, han realizado una suerte de difusión de un mensaje implícito de felicitar y promover la violencia que se ejercía en las protestas sociales, y que también ello conduciría a un objetivo, en este caso el de la destitución del Presidente Manuel Merino.

Las transmisiones en casas televisoras, así como radiodifusoras e incluso la prensa escrita que cedió un amplio espacio a este tipo de sucesos.

El rol fundamental de las redes sociales Importar lista

De igual modo, las redes sociales se volvieron una suerte de herramienta indispensable para la coordinación y difusión de determinadas protestas sociales convocadas por organizaciones y colectivos sociales que generalmente están integradas por grupos vulnerables.

También otro beneficio de las redes sociales es que otorga un espacio más pacífico y sosegado para los interesados en participar de dichas manifestaciones sociales, de esa manera se evita la tensión propia de los encuentros presenciales, y consecuentemente evitar la posibilidad de realizar conductas delictivas de parte de los manifestantes.

El rápido acceso a la información en redes sociales sobre la Marcha de la Generación del Bicentenario ocasionó un control tanto sobre la represión del personal policial contra los protestantes, así como, en la búsqueda y posterior hallazgo de las personas desaparecidas en dichas marchas, al momento de compartir las listas de desaparecidos, después de las manifestaciones.

\section{ANÁLISIS DOGMÁTICO DE LA CRIMINALIZACIÓN DE LA PROTESTA DESDE LA LEGISLACIÓN PENAL PERUANA}

En el Perú particularmente, la estrategia de disuasión de los movimientos sociales por medio de la punición, tienen sus antecedentes más visibles en el gobierno de Alberto Fujimori, en el que se dictaron normas sumamente represivas contra movimientos y líderes sociales, bajo el aparente propósito de luchar contra el "terrorismo agravado". Esta política no se modificó en el régimen de Alejandro Toledo y por el contrario continuó aplicándola, sobre todo penalizando, así delitos que estaban relacionados a las protestas sociales, tales como los bloqueos de carreteras. Toledo facilitaba así el afianzamiento de la política neoliberal de Fujimori. Pero sin duda ha sido el gobierno de Alan García el que más abierta cercanía ha tenido con los grupos económicos y consecuentemente ha sido el más confrontacional y agresivo con los movimientos sociales, especialmente con los de defensa del medio ambiente y los grupos sindicales, a quienes no dudó en calificar de "perros del hortelano", "enemigos de la patria" o "anti desarrollo", y contra los cuales generó 
un vasto conjunto de normas jurídicas para criminalizarlos y neutralizarlos, no escatimó para ello en el uso indiscriminado de la fuerza pública, la militarización de zonas en conflicto, la utilización de leyes contra autoridades locales comprometidas en estas causas, entre otras medidas. (Vásquez, 2011)

En la actualidad en el país, se puede visualizar la materialización de la criminalización a través de la promulgación de normas novísimas, sumado a ello el uso de mecanismos para la represión y punición de la protesta social; esta situación tiene un crecimiento peligroso. La mayor cantidad de estas protestas tienen una relación directa con los problemas ambientales, sin embargo, el 2020 esto dio un giro, y las protestas se desarrollaron en un contexto político, en ese sentido los manifestantes mostraron una oposición al sistema de gobierno corrupto, sumado a la crisis sanitaria por el Covid-19.

1.- Indicios de la política de criminalización

La criminalización de la protesta social es una política deliberada que asumen los gobiernos para evitar la oposición evidente y manifiesta de sus oponentes. No se reduce a acciones concretas o aisladas como la represión, sino que implica toda una estrategia, con medidas sistemáticas, en distintos ámbitos, apuntando todas a la consecución de un fin específico, neutralizar la protesta y al protestante, a quienes el poder político y/o económico considera fuerzas intolerables. Por tanto, para considerar que estamos frente a una política de criminalización de Protesta Social se debe verificar el despliegue de esta estrategia en todo el aparato del Estado, sus poderes (ejecutivo, legislativo y judicial), sus medios (mediáticos- comunicacionales) y sus fuerzas (armadas y policiales). Esta estrategia necesariamente está en el campo institucional y legal para contrarrestar a los considerados "adversarios" o "enemigos"; tal vez el más visible es la utilización de la fuerza pública o violencia legal por parte del Estado, sin embargo, existen otros mecanismos que son menos perceptibles, pero que sin duda se convierten en indicadores determinantes para afirmar que estamos frente a esta estrategia. (Vásquez, 2011).

1.1.- La utilización de y manipulación del sistema legal

Viene constituyendo un elemento fundamental, pues es en este plano que el gobierno suele moverse con más facilidad, usa los tipos legales genéricos, modifica normas específicas para ajustarlas a las situaciones, crea y promulga leyes que persigan, sancionen o sobre penalicen todo lo relacionado a la protesta social. (Vásquez, 2011).

1.2.- La utilización prioritaria de la vía penal

Ha existido una serie de reformas normativas para procurar la neutralización de la protesta social, sin embargo, la mayoría está en el campo de las normas penales, es decir hay un claro objetivo de asociar la protesta social con lo criminal y de presuponer que sus resultados siempre son delictivos. Con ello, a los actores de la protesta o manifestantes también se los asocia con la condición criminal, provocando que al ser juzgados el tratamiento sea el mismo que se le da a cualquier delincuente común. Se usa tanto tipos penales usuales cuyo bien jurídico protegido es la paz y la tranquilidad pública o la propiedad (disturbios, entorpecimiento al funcionamiento de los servicios públicos, atentado contra los medios de transporte, daños, etc.), como también tipos penales particulares que se adecuan ex profesamente para hacer calzar en ellos acciones relacionadas a la movilización; un claro ejemplo de ello es la utilización de la figura de Extorsión (un delito netamente económico) modificado en sus presupuestos de tal forma que ahora entra en este tipo delictivo las acciones de protesta. (Vásquez, 2011).

De igual modo se verifica que se está procesando judicialmente los actos de protesta social bajo los tipos delictivos de Rebelión, Conspiración o Motín, lo que significa que se considera a la Protesta Social como un atentado contra los poderes del Estado y el orden constitucional, situación que no caracteriza a la movilización ciudadana y que más bien evidencia una clara intencionalidad de procurar sanciones más rigurosas y crear mayor presión y amedrentamiento en los perseguidos.

También se ha intentado utilizar la figura de Terrorismo para equipararla a la Protesta Social pretendiendo con ello, sin duda, la aplicación de las sanciones más severas que existe en nuestro sistema penal, incluyendo la cadena perpetua. 
De manera recurrente también se está calificando toda convocatoria a actos de protesta o movilización como "Apología al delito" y considerando a los líderes de los movimientos sociales como "instigadores", limitando así el derecho a la libre expresión y su ejercicio, lo que resulta absolutamente incongruente con la democracia.

1.2.1.- La Sobre Penalización de delitos relacionados a la protesta social

La tendencia de estos dos últimos gobiernos ha sido sin duda funcionalizar el orden penal para conseguir que la protesta social se encuadre en los marcos del delito, pero una de las estrategias privilegiadas y más prácticas ha sido realizar un sistemático ajuste en las sanciones o penas de los delitos relacionados a la protesta social, elevándose gradualmente; así, los delitos contra la tranquilidad y paz pública que diez años atrás no tenían penas privativas de libertad mayores a dos años y en su modalidad agravada tenía un máximo de seis, ahora son penalizadas hasta con 8 y 10 años respectivamente. (Vásquez, 2011).

1.3.- Denuncia y persecución legal Selectiva

La política de criminalización, se caracteriza por ser "selectiva” y eso plantea que no es cualquier persona la que es blanco de esta "persecución" sino que prioriza a quienes ostentan determinado liderazgo social ya sea como autoridad, como representante de organizaciones o simplemente quienes adquieren visibilidad durante la situación de protesta, y es que el método apunta a quebrar el movimiento social el cual se puede lograr fácilmente a partir de los liderazgos. Solo por ejemplificar este aspecto, en el conflicto importante para el país por la ejecución del Proyecto minero Conga, se aperturó investigaciones penales contra un promedio de trescientas personas, y aunque sería largo colocar la lista de los mismos, está claro que estas personas no son un grupo indiscriminado de ciudadanos que son procesados por excesos en las protestas, sino que cuando menos el $90 \%$ de los mismos son líderes sociales o autoridades visibles y con posturas abiertamente críticas al gobierno. (Vásquez, 2011).

1.4.- El delito de Disturbios

Se encuentra dentro del título de delitos contra la tranquilidad pública. La doctrina nacional dice que son "delitos de alarma colectiva" (...) Es la indefectible presencia de este efecto lo que la ley tiene en cuenta para agruparlos en una clase especial. Se les reprime no porque lesionan la paz social, sino porque al producir la alarma colectiva, atacan el derecho a la tranquilidad que tienen todas las personas" (Bramont, 1995).

Se encuentra tipificado en el artículo 315 del Código Penal. Por consiguiente, su actual redacción es:

Artículo 315, "el que, en una reunión tumultuaria, atenta contra la integridad física de las personas y/o mediante violencia causa grave daño a la propiedad pública o privada, será reprimido con pena privativa de libertad no menor de seis ni mayor de ocho años.

En los casos en que el agente utilice indebidamente prendas o símbolos distintivos de las Fuerzas Armadas o de la Policía Nacional del Perú, la pena privativa de la libertad será no menor de ocho años ni mayor de diez años".

Es necesario mencionar que con la Ley 27686 se modificó el texto original del artículo 315 del Código Penal, con el objetivo de incrementar las penas requeridas; y que en julio de 2006 se dictó la ley 28820 que aumentó el marco de la sanción penal.

La jurisprudencia sobre la materia ha establecido de manera general que para su configuración se requiere una pluralidad de personas, el ejercicio de violencia y capacidad de poner en peligro la tranquilidad pública: vale decir que el agente haya actuado colectivamente y con violencia contra las personas o contra las propiedades, la intervención de una pluralidad de personas en la alteración del orden público, que ha de verificarse a través de la violencia, que el agente participe en una multitud capaz de poner en peligro la tranquilidad pública, alterando el estado psicológico de una población al crear ésta un estado de inseguridad; también se ha decantado por la atipicidad de comportamientos tales como la reacción colectiva de indignación motivada por la escasa valoración de las acciones de la empresa en venta; al respecto, puede considerarse que el hecho en cuestión fue una respuesta a estímulos externos, una acción espontánea tendiente a evitar la venta de las acciones bajo las condiciones propuestas. (Bertoni, 2013). 


\section{INTERPRETACIÓN CRIMINOLÓGICA DE LOS RESULTADOS ALCANZADOS CON LAS ENCUESTAS VIRTUALES 2021}

Según la encuesta realizada por Google Forms en fecha 01 de febrero al 17 de febrero del año en curso, en la cual participaron alrededor de 100 personas, se obtuvieron los siguientes resultados:

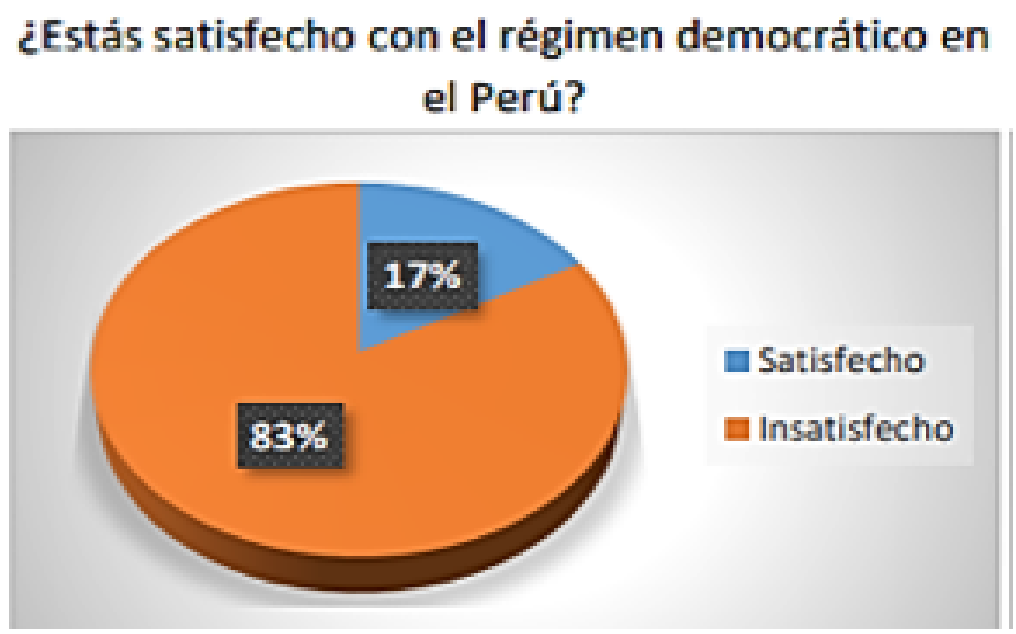

FIGURA 1

Nota: El gráfico estadístico representa el 86.4 por ciento de la población de entre los 18 a 35 años, de los cuales la mayoría son del género femenino, un 84.1 por ciento se muestran insatisfechos con el actual régimen democrático en el Perú.

Ciertamente resulta interesante debido a que comprueba que son ciertos grupos vulnerables los cuales expresan su disconformidad con el actual régimen democrático en el Perú por razones de edad y género, y ello se ve reflejado en las repetidas protestas que realizan estos determinados grupos, algunos a través de colectivos

\section{¿Estás de acuerdo con las protestas sociales?}

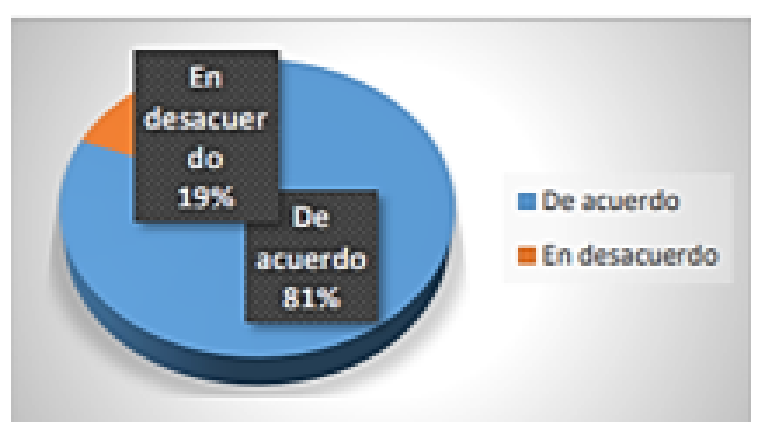

FIGURAS 2 Y 3 


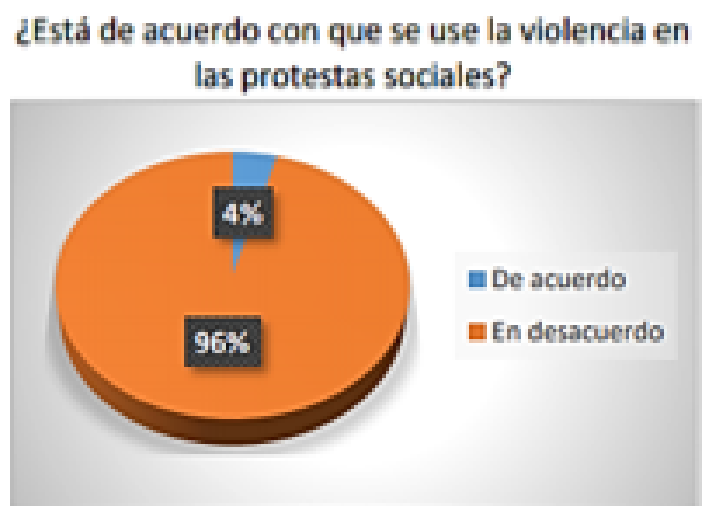

Nota: Del mismo modo, el 81.6 por ciento se muestra conforme con la realización de las protestas sociales, no obstante, un 95.5 por ciento está en desacuerdo con el uso de la violencia en las mismas, y en este sentido, en la actualidad las redes sociales están formando un papel protagónico para su realización, siendo usado como una herramienta fundamental en su desarrollo.

Ante los datos recabados, la población considera que resulta necesario realizar una protesta social frente a una situación que resulte injusta, pese a ello no está de acuerdo con el uso de la violencia más por el contrario se deba de realizar una protesta social pacífica, en base a ello hacen sus convocatorias a través de las redes sociales y de esa manera se evita la exposición a estímulos nocivos entre protestantes, que fomentaría la tensión y que puede desencadenar en reacciones delictivas.

\section{$¿$ Crees que las redes sociales son una herramienta útil para la protesta social?}

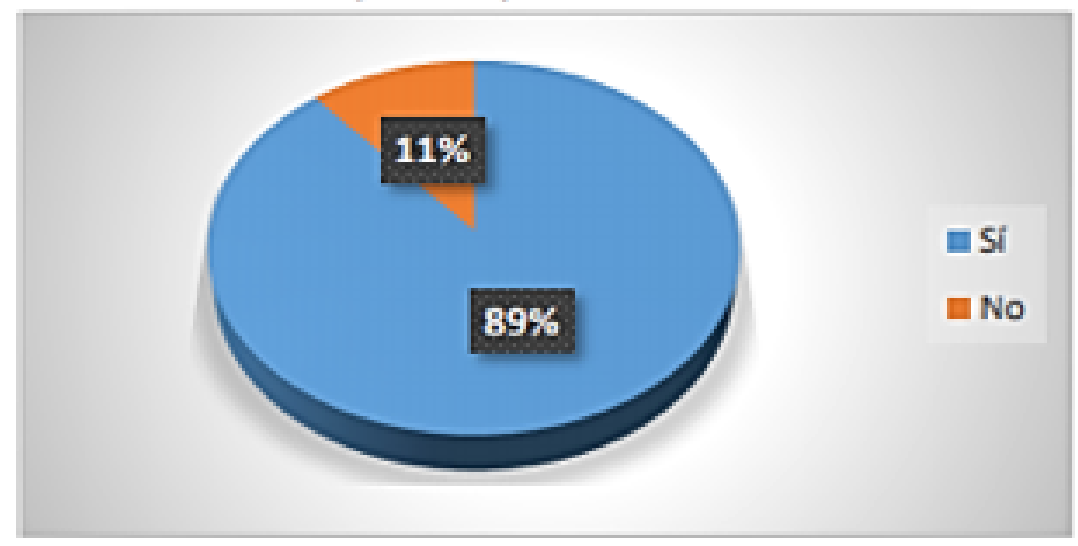

FIGURA 4

Nota: Al respecto la actitud de los encuestados respecto a las marchas, protestas sociales reflejan que un 50.6 por ciento, aunque no participó en dichas protestas sociales, sí las apoya, frente a un 27.6 por ciento que sí ha participado y apoyado las marchas de las protestas sociales.

La represión policial tiene un papel protagónico en las protestas sociales en el Perú, pues ha generado abuso y violencia en los protestantes, ello se ve reflejado en la opinión del 87.5 por ciento de encuestados, y que se ve estrechamente relacionado con los resultados del 70.9 por ciento que considera que no se practica ningún valor dentro de la sociedad peruana, dejando un 3 por ciento al diálogo como el valor menos practicado, finalmente entre los encuestados prepondera la idea de justicia en un $44.4 \%$, conjuntamente con la democracia del 25.6 por ciento. 


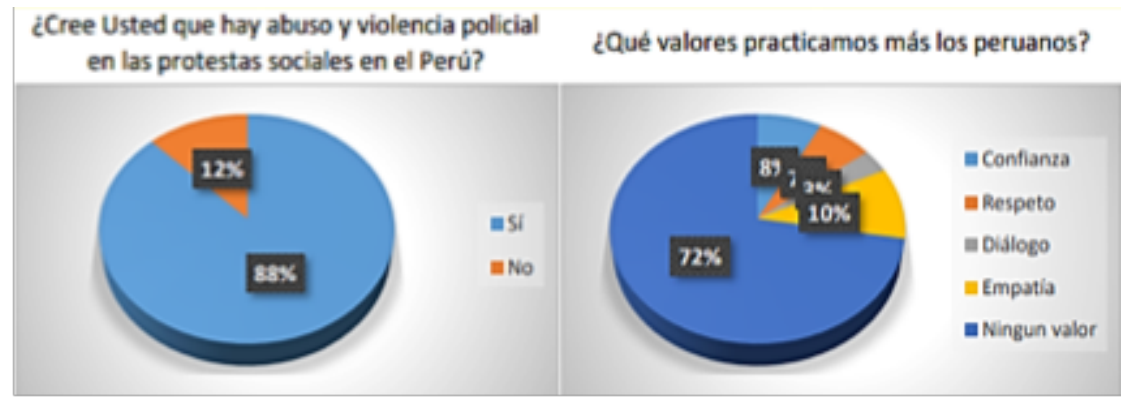

FIGURAS 5 Y 6:

Nota: De ello, señalamos que aquí hablamos del poder de polícia, lo que nos menciona el maestro Eugenio Zaffaroni, en donde se hace referencia a un estado represivo, más aún en un país en el cual se considera que su población no desarrolla ni practica ningún valor, donde la población pide justicia y democracia, sin embargo, la respuesta del estado es represiva por medio de una institución pública, cual es la Policía Nacional del Perú.

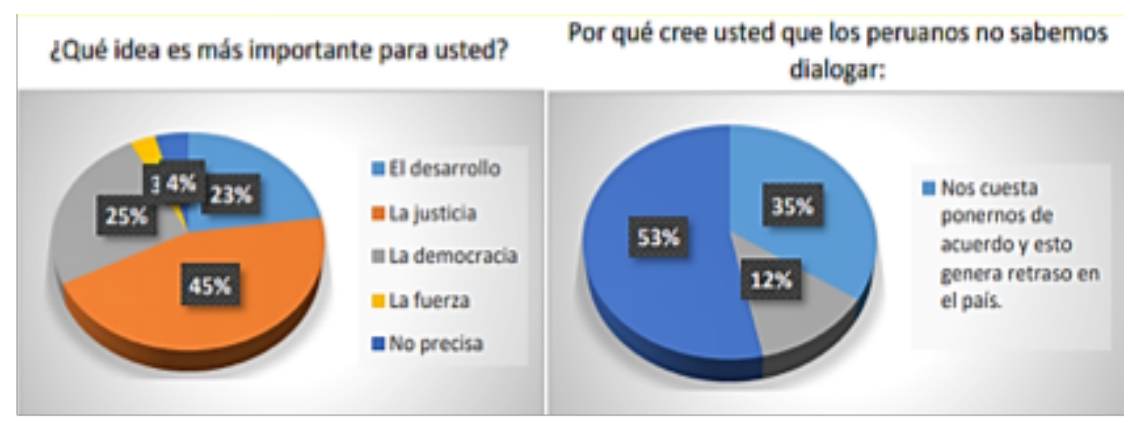

FIGURAS 7 Y 8

Nota: En relación a ello también se indica que el 52.9 por ciento cree que los peruanos no sabemos resolver nuestros problemas a través del diálogo, y como lo mencionado anteriormente al no practicar ningún valor en la sociedad peruana en consecuencia un 48.2 por ciento considera que los peruanos para triunfar deben estar bien relacionados.

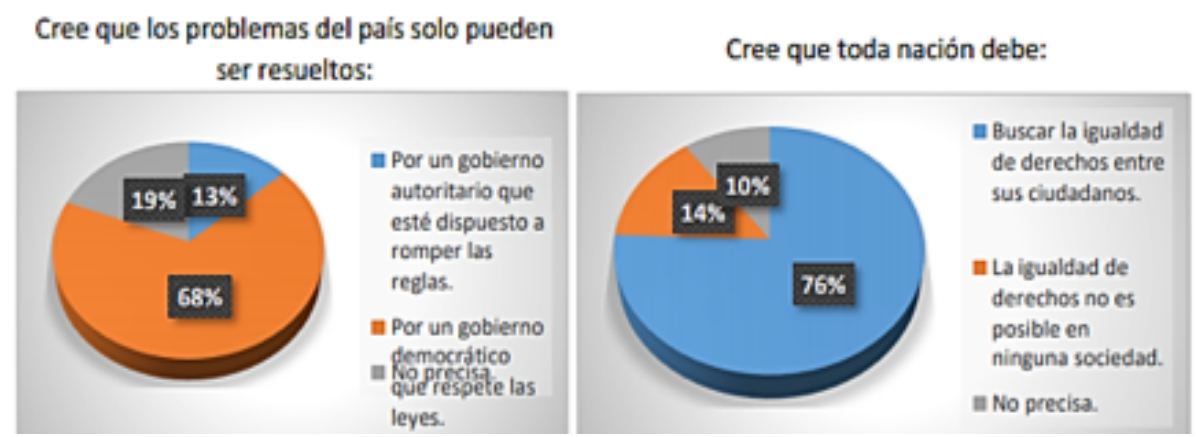

FIGURAS 9 Y 10

Nota: El 69 por ciento de los encuestados cree que los problemas del país solo pueden ser resueltos por un gobierno democrático que respete las leyes, asimismo, un 75.9 por ciento considera que toda la nación debe buscar la igualdad de derechos entre sus ciudadanos, y el 34.1 por ciento que opina que la acción más importante para ser un país mejor es ver nuestra diversidad como riqueza.

Entonces, la mala organización del estado es lo que finalmente provoca la desigualdad de oportunidades generando tensión y frustración en los determinados grupos que pasan a ser vulnerables, y que según la teoría de las oportunidades diferenciales las conductas desviadas surgen en los jóvenes cuando sienten que lograr el éxito social está obstruido, en base a sus pocas oportunidades educativas y económicas y que a futuro condiciona el desarrollo de su vida. Dado que, si se busca la igualdad se evitan los conflictos sociales al no haber exclusiones de ningún grupo social.

Por ello se hace necesario la construcción de un estado democrático que respete los derechos de los ciudadanos y que responda oportunidades frente a la necesidades o problemas que se podrían generar dentro 
de esta, mientras que para la sociedad sería el considerar ver como oportunidades la diversidad de riqueza existentes dentro de su propio contexto como una forma de desarrollo personal y social, en colectividad.

\section{CONCLUSIONES}

Primero, se concluye que si bien es cierto el derecho a la protesta es considerado como un derecho fundamental, asimismo que no se puede negar que en la práctica reciente de las manifestaciones sociales en tiempos de pandemia ha sido utilizado efectivamente como medio para conseguir determinados objetivos frente a situaciones que resulten injustas o que afecten a intereses de la colectividad.

Sin embargo, no existe justificación alguna para el empleo de la violencia por ninguna de las partes, ni protestantes o fuerzas policiales, muy por el contrario, se deben usar medios alternativos más pacíficos y sosegados como las redes sociales mediante las cuales se emplea un diálogo fluido y libre de tensión.

Segundo, la tendencia socio criminológica explica mediante su teoría de la tensión o frustración que sienten los sujetos que integran ciertos grupos vulnerables dentro de nuestra sociedad que se encuentran expuestos a estímulos negativos, un ejemplo de ello, se demuestra en los resultados de la presente investigación a través de las figuras presentadas, que indican que en su mayoría son jóvenes entre el rango de 18 a 35 años, del género femenino.

Y que por ende se enfrentan a situaciones de desigualdad de oportunidades educativas, económicas, y entre otros aspectos relevantes para su desarrollo personal y social. Encontrando así en las protestas sociales una vía de búsqueda de la justicia, no obstante, el gobierno no realiza un tratamiento adecuado y oportuno con referente a estas protestas sociales lo que desencadena en que la situación se llegue a agravar.

Finalmente, ante tal preocupante escenario en nuestro país el grupo que realiza la presente investigación ha llegado a la conclusión de que se hace necesaria la construcción e implementación de una política criminal.

Esta sería orientada a realizar un tratamiento adecuado y previo a la criminalización y consiguiente judicialización de las protestas sociales, lo que se busca es solucionar las causas del conflicto social para evitar la violencia en las manifestaciones, cuidando y velando por los derechos de los protestantes, así como de las fuerzas del orden.

De este modo se propone otorgar a los informes de la Defensoría del Pueblo un peso de mayor obligatoriedad, asimismo que ejerza un rol más activo, que puede ser ejercido mediante la conciliación con representantes legítimos tanto de parte de los protestantes como de las fuerzas del orden. Para ello, se debería cambiar la competencia de la Defensoría del Pueblo para emitir “resoluciones defensoriales”. Además, de una posible "Alianza de Cooperación Política" para casos donde exista más de un grupo en actos de protestas al mismo tiempo. De esta manera se alcanzaría la utopía de vivir en una sociedad democrática, pacífica y en armonía.

\section{BIBLIOGRAFÍA}

BERTONI, E. A. (2013). ¿Es legítima la criminalización de la protesta social?: derecho penal y libertad en América Latina. In Convergencia (Vol. 20).

Bramont Arias , L. A., \& Bramont-Arias Torres, L. A. (1995). Código penal anotado. Lima : Editorial San Marcos.

Coronel, O. (22 de Mayo de 2020) Perú: pandemia y respuestas de una sociedad débil. Recopilado de: https://www.cipe rchile.cl/2020/05/22/peru-pandemia-y-respuestas-de-una-sociedad-civil-debill

Manzo Ugas, G. A. (2018). SOBRE EL DERECHO A LA PROTESTA. NOVUM JUS, 17-55. Recuperado el 18 de Diciembre de 2020, de https://repository.ucatolica.edu.co/bitstream/10983/16343/1/Sobre\%20el\%20derech o\%20a\%20la\%20protesta.pdf

PALAO QUIROZ, G.A. FACULTAD DE DERECHO LA PROTESTA SOCIAL EN DEMOCRACIA\#: UNA CONFIGURACIÓN CONSTITUCIONAL DE LA PROTESTA SOCIAL DESDE EL ANÁLISIS DE LAS 
Dyanna Solange Paredes Ponce, et al. La CRiminalización y JUdicialización de LaS PROTeSTaS SOCIALE...

CONTRA EL RÉGIMEN LABORAL JUVENIL Tesis para optar por el Titulo de Abogado que presenta el Bachiller\#: GONZALO ALONSO P. (2019).

Quintero Guevara, D. (19 de Noviembre de 2019). Pares. Obtenido de Pares: https://pares.com.co/2019/11/19/las -normas-internacionales-que-protegen-el-derecho-a-la-protesta/

Relatoría Especial para la libertad de expresión. (2019). Protesta y Derechos Humanos.

Vásquez, M. (2011). LA CRIMINALIZACION DE LA PROTESTA SOCIAL COMO ESTRATEGIA DE DESARTICUL ACION DEL MOVIMIENTO SOCIAL EN EL PERÚ. https://grufides.org/sites/default/file s//documentos/documentos/Criminalizaci\%C3\%B3n\%20de\%20la\%20Protesta\%20ult.pdf 